\title{
DossIER
}

Problemas Ligados ao Álcool

\section{Prevenção dos problemas ligados ao álcool em cuidados primários de saúde}

\author{
M. F. CLEMENTE LIMA, ${ }^{*}$ C. RIBEIRO**
}

\section{RESUMO}

Os problemas ligados ao álcool têm vindo a aumentar ao longo dos anos, apesar de cada vez mais se estar a investir no tratamento da dependência alcoólica. A prevenção do alcoolismo, assim como do consumo de risco e nocivo, deve envolver uma actuação concertada de vários sectores da sociedade. A informacão do individuo pressupõe formacão, o que lhe confere a capacidade de fazer escolhas esclarecidas. Grande parte desta informação passa pelos profissionais da saúde e particularmente pelos cuidados primários e respectivos agentes envolvidos. Quanto mais temos que intervir em prevenção secundária e terciária mais significa que falhámos relativamente ao primeiro nível de prevencĩo.

Conclusão: Mais que uma discussão exaustiva de tudo o que pode ser feito relativamente à prevenção dos problemas ligados ao álcool a nivel dos cuidados primários, pretende-se alertar os profissionais de saúde e nomeadamente os médicos de família para a importância da precocidade da sua intervenção na área da prevenção primária, salientando que isso passa também pela sua capacidade de informar e formar, não só a população em geral, mas também os agentes envolvidos nesta área de actuação. Neste texto os autores fazem portanto uma abordagem da prevenção dos problemas ligados ao álcool através uma reflexão sobre o papel dos cuidados de saúde primários nesta matéria. É de salientar os tipos de prevenção existentes, utilizando para o efeito classificações que convergem para uma abordagem que deverá ser cada vez mais proactiva no sentido de promover estilos de vida saudáveis.

Palavras Chave: Prevenção; Alcoolismo; Cuidados de Saúde Primários; Rastreios.
*Assistente Graduada de Clinica Geral Centro de Saúde de Gouveia

**Assistente Graduada de Clínica Geral Centro de Saúde de Sete Rios. Docente Faculdade de Medicina da Universidade de Lisboa

\section{REFLEXÕES}

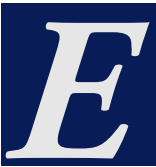

m pleno século XXI a sociedade, nomeadamente a portuguesa, vê-se a braços com um problema de saúde pública cuja essência remonta a hábitos que vêm dos primórdios da humanidade, o consumo exagerado de bebidas alcoólicas.

E se, ao longo dos séculos, o Homem inseriu nos seus usos e costumes a ingestão deste tipo de bebidas, foi também o homem que as tornou cada vez mais graduadas e que descurou a modera- ção do seu uso, com consequências nefastas para a sua própria saúde.

Contudo, mais que um problema social, o consumo excessivo de bebidas alcoólicas deve ser visto essencialmente como um problema do indivíduo.

O mesmo individuo que, ao longo das últimas décadas, viu desmoronar à sua volta o seu "grupo", simultaneamente o garante da sua força e do seu modo de estar na sociedade. O primeiro talvez a família, que cada vez é menos tradicionalmente nuclear, depois talvez o clube desportivo favorito, em que os valores económicos subjugam os da prática saudável do desporto, espírito de equipa, camaradagem. A seguir a associação de bairro, o partido político, o grupo de amigos, a escola, onde cada vez mais a competitividade é estimulada em detrimento da aprendizagem e do bem-estar social.

$\mathrm{E}$ assim, ao longo dos anos, a força que emanava do "grupo" para dentro de si deixou de ter sentido num indivíduo, tradicionalmente fraco, enquanto sozinho, por não lhe ter sido até então necessária a procura de si próprio e da sua cultura como pessoa.

Todos nós, médicos de família, ouvimos centenas de vezes o nosso doente culpar os amigos, a família, o emprego, quando questionado sobre os excessos dos seus hábitos alcoólicos. A culpa nunca é assumida mas sim direccionada para algum sector da sociedade de 
cuja responsabilidade ele próprio se demite.

Também para prevenir o alcoolismo é necessário formar o indivíduo. $\mathrm{E}$ a formação do indivíduo não pode nem deve ser sectorial, mas sim um trabalho conjunto de todos, com um grande empenho de cada um de nós.

E é aqui que, como profissionais de saúde, temos um importante papel a desempenhar num enquadramento, forçosamente mais alargado a todos os sectores da sociedade.

E se quando nascemos não sabemos falar, nem andar, nem conseguimos por nós próprios angariar meios de subsistência, começando a nossa aprendizagem pelo nosso próprio princípio, face aos condicionantes que nos rodeiam, também para formar o indivíduo não podemos começar pelo meio nem pelo fim.

$\mathrm{O}$ investimento tem de ser iniciado nas idades mais jovens, no ensino básico, quiçá mesmo no pré-escolar, prolongando-se pelas várias fases da vida.

E esse investimento passa:

- pela informação de conceitos básicos mas perfeitamente claros;

- pela sensibilização de todos os intervenientes para a existência do alcoolismo como problema;

- pelo conhecimento correcto dos hábitos de consumo de bebidas alcoólicas que o podem gerar.

Ninguém discute que o consumo exagerado de bebidas com teor alcoólico faz mal à saúde. Mas toda a gente sabe porque é que as crianças, os adolescentes e as grávidas não as devem consumir? Será que todos sabem que a ingestão de mais de dois copos de uma qualquer bebida alcoólica/dia pode ser considerado já um consumo excessivo? $\mathrm{E}$ com que factores varia a taxa de alcoolemia? E como é que o seu valor elevado pode condicionar determinadas alterações a nível fisico e psicológico?

Estas e muitas outras interrogações devem ser esclarecidas pelos profissio- nais de saúde face aos vários intervenientes porque, neste palco (onde todos somos simultaneamente actores principais, figurantes e espectadores), apesar de cada um ter um tom de voz diferente as "deixas" têm que ser iguais, se quisermos representar a mesma peça. $\mathrm{E}$ isso envolve não só profissionais de saúde como pais, educadores e todas as forças vivas da comunidade.

Depois é importante estarmos atentos às alterações do comportamento, interno e externo do indivíduo. Mas para isso temos de ter consciência de que o alcoolismo existe e sermos capazes de estar despertos para os seus sinais de alerta.

Alerta para os primeiros sinais de perigo, sinalizando-os o mais precocemente possivel: na família (as alterações de humor, o desinteresse, os conflitos frequentes), na escola (uma criança sonolenta, desatenta, com dificuldades de aprendizagem, uma mudança súbita do grupo de amigos), no trabalho (o abstencionismo continuado, uma baixa de rendimento, os conflitos laborais, os sucessivos acidentes).

Prevenir é sempre a melhor forma de evitar a doença.

Fomentar estilos de vida saudáveis envolvendo todos os sectores da nossa comunidade terá de ser certamente um dos caminhos a seguir.

Informar, explicar porquê, comprometer em todo o processo as diferentes faixas etárias e os diversos intervenientes da comunidade.

Criar alternativas a locais de encontro onde haja maior risco de consumo de bebidas alcoólicas (incentivar p. ex. a prática de desporto, grupos de ajuda, investir em espaços de leitura, pintura, dança, teatro).

A prevenção dos problemas ligados ao álcool passa essencialmente pela informação e formação continuada do indivíduo, das quais os profissionais de saúde não se devem demitir e onde reside a grande responsabilidade da sociedade. 
Depois... bom depois, como tudo na vida, a escolha é de cada um!

\section{Nívels de Prevencão}

\section{Primária}

Se até agora se tem investido no acompanhamento terapêutico do doente alcoólico com a criação de unidades específicas para o seu tratamento (a nivel regional, distrital e concelhio), é cada vez mais importante o investimento dos profissionais de saúde na prevenção do consumo de risco, nocivo e da dependência alcoólica como doença. Estabelecer programas de promoção da saúde em conjunto com os vários sectores da comunidade, promovendo estilos de vida saudável, nomeadamente no que diz respeito aos hábitos alimentares $\mathrm{e}$ de diversão (onde a ingestão de bebidas alcoólicas está presente) é seguramente uma forma importante de intervir.

Prestar informação correcta e concertada no sentido de esclarecer a população em geral e grupos de risco em particular sobre a diferença entre o uso e o abuso das bebidas alcoólicas é o garante de uma liberdade de escolha esclarecida por parte de cada um.

Tal como os pais devem ter, entre os dois, o mesmo tipo de linguagem para uma educação equilibrada dos seus filhos, é igualmente importante que todos os intervenientes no processo tenham os mesmos conceitos básicos no que diz respeito ao consumo de bebidas alcoólicas.

A sensibilização dos médicos de família para o investimento nesta causa, nomeadamente nas consultas de hiper- tensão, diabetes, materno-infantil, de adolescentes é da maior importância na prevenção de danos.

O estar alerta a grupos e consumos de risco pode evitar males futuros para a saúde do indivíduo e encargos desnecessários para a sociedade. Talvez por isso nos tenhamos que sentir um pouco culpados quando temos que actuar na segunda etapa de prevenção, porque é sinal que falhámos no primeiro nivel.

\section{Secundária}

Entramos então no âmbito da prevenção secundária onde, através de intervenções breves ligadas ao álcool podemos, como médicos de família, sinalizar casos problema e desde logo iniciar a parte motivacional com intuitos terapêuticos.

A aplicação do AUDIT dá-nos uma ideia do tipo de consumos e da sua potencial severidade (http://www.cras. min-saude.pt/AUDIT_question\%E1rio. pdf) e é um questionário apropriado para os Cuidados de Saúde Primários porque permite detectar consumo de risco, nocivo e dependência alcoólica.

Quando o nosso utente admite ingestão de bebidas alcoólicas, o CAGE é um bom questionário para rastreio do dependência alcoólica, devendo considerar-se "positivo" se uma das respostas for "sim" (Ver Quadro).

A dependência alcoólica é uma doença plurifactorial, pelo que o investimento no seu tratamento deve passar também por equipas multidisciplinares.

O doente alcoólico nem sempre admite ou tem consciência da sua doença, o que leva muitas vezes a que a sua adesão à terapêutica seja morosa e neces-

\begin{tabular}{l|l|l|l} 
C & (cut down = diminuir) & Alguma vez sentiu que deveria diminuir a quantidade de bebida?
\end{tabular}

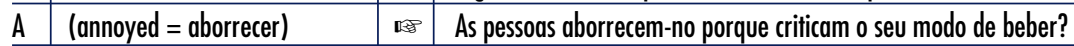

\begin{tabular}{ll|l|l}
\hline $\mathbf{G}$ & (guilt $=$ culpa) & Sente-se culpado pela maneira como bebe? \\
\hline
\end{tabular}

$\mathrm{E}$ (eye opening = a despertar) 


\section{DOSSIER}

Problemas Ligados ao Álcool

site de uma grande persistência por parte dos profissionais envolvidos. Por outro lado, o seu tratamento apresenta grande taxa de insucessos. Daí a importância de equipas vocacionadas para o tratamento deste tipo de patologia, capazes de lidar com as recaídas, encarando-as como uma das etapas do programa de recuperação.

A opção pelo tipo de tratamento (em ambulatório ou internamento) terá de ser decidida, caso a caso, consoante o grau de dependência e o estado geral de saúde do indivíduo. E se o primeiro se afigura de maior acessibilidade, a articulação com serviços ou comunidades terapêuticas deve, cada vez mais, ser eficaz em termos de resposta, face a um doente que fácilmente se desmotiva.

Os grupos de auto-ajuda, como os de alcoólicos recuperados, são de extrema importância na área motivacional e na persecução do tratamento, tal como importantes são o acompanhamento das famílias do doente alcoólico e o iniciar, tão breve quanto possivel, a sua reinserção social e laboral.

\section{Terciária}

Após o programa terapêutico anterior, é fundamental o acompanhamento do doente alcoólico tratado, intervindo sempre que necessário no auxilio relativo à mudança de hábitos e comportamentos, com o intuito da prevenção das recaídas ou da redução de danos.

Também aqui os grupos de auto-ajuda e a continuidade do programa de reinserção assumem um papel de grande relevância.

\section{a interface da Prevencéo e CuIdados de SaÚde PrimárIos}

Embora não haja uma única definição, o termo prevenção, na área do uso de substâncias, diz respeito a qualquer actividade realizada no sentido de reduzir ou adiar o início do abuso de uma subs- tância e previne a progressão para um uso mais pernicioso entre as populações em risco. ${ }^{1}$

Tradicionalmente, o modelo de saúde pública representa a matriz conceptual donde emergiram as intervenções preventivas. ${ }^{2}$ Assim, os conhecimentos do ponto de vista do trabalho preventivo devem ser direccionados para acções que reduzam as probabilidades de um indivíduo usar inadequadamente uma substância incidindo no fortalecimento dos factores protectores e reduzindo os factores de risco (prevenção primária); que interrompam o consumo nocivo e dependência de substâncias, como é o caso das detecções oportunísticas seguidas de intervenções breves (prevenção secundária); que mantenham o indivíduo abstinente a longo prazo e a reinserção (prevenção terciária).

$\mathrm{O}$ instituto de Medicina nos EUA American Institute of Medicine ${ }^{3}$ - propôs uma nova classificação para a prevenção, com as designações de prevenção universal, selectiva e indicada. Assim, as estratégias de prevenção universal têm como alvo a população geral, seja a nível local, na comunidade, na escola, e visam prevenir ou adiar o consumo nocivo de qualquer substância. A prevenção selectiva já diz respeito a estratos da população que apresentam determinadas características específicas que já os podem colocar em risco, como por exemplo serem filhos de pais alcoólicos ou terem problemas de natureza social que os leva a abandonar a escola. A prevenção indicada visa prevenir o consumo nocivo ou dependência em indivíduos que já têm um padrão de consumo com alguns sinais e sintomas detectados pelo profissional de saúde numa fase inicial do processo. ${ }^{4}$

Repare-se que nesta perspectiva de encarar prevenção, pretende-se reduzir o número de novos casos, investindo essencialmente, quer na redução dos factores de risco, quer no desenvolvimento dos factores protectores. O consumo 
nocivo e a dependência têm na sua origem interacções complexas de factores biológicos, sociais e psicológicos que variam em função do estádio de desenvolvimento do individuo. ${ }^{5}$ Assim podem-se identificar dimensões na qual podemos encontrar factores de risco e factores protectores, nomeadamente individual e grupo de pares, familiar, escolar e comunitária/social. A relação entre factores de risco ou factores protectores dentro de cada dimensão pode condicionar a maturação emocional e cognitiva do individuo, o que pode vir a moderar ou agravar a relação com as substâncias e desse facto condicionar a utilização mais precoce da mesma.

$\mathrm{Na}$ medicina geral e familiar, o foco da atenção na prestação de cuidados de saúde é a pessoa integrada no seu contexto familiar e comunitário e, para além de um trabalho dirigido para a cura e o alivio das doenças, há que ter em conta o papel que deverá ser cada vez mais activo nas áreas de carácter preventivo: ${ }^{6}$

- O médico de família tem acesso a uma população definida e pode identificar com maior facilidade os que estão expostos a factores de risco e a factores protectores, o que constitui um dos aspectos mais importantes de uma acção preventiva.

- O médico de família vê cada utente em média quatro vezes por ano, o que constitui uma excelente oportunidade para o exercício da medicina preventiva.

- Cerca de $65 \%$ dos utentes consulta o seu médico de família pelo menos uma vez por ano e $90 \%$ pelo menos uma vez em cinco anos.

- Muitas actividades preventivas são mais efectivas quando aplicadas à família.

- A relação médico-doente que existe em Medicina Geral e Familiar é um dos factores mais influentes na adesão às actividades preventivos. O médico de família é conhecedor das crenças de saúde dos seus utentes o que permite dirigir a informação, mais facilmente assimilável, sobre determinados conteúdos.

- O médico de família pode gerir melhor as actividades preventivas, combinando-as com o diagnóstico e o tratamento.

O médico de família, integrado numa equipa de cuidados de saúde primários e dada a natureza e continuidade de cuidados que presta, está numa posição privilegiada para uma prática preventiva sustentada por evidências científicas adequadas. De entre os procedimentos preventivos utilizados pelo médico de família, contam-se a detecção oportunística de casos e os rastreios cuja aplicação deve obedecer a princípios fundamentais, nomeadamente: ${ }^{6}$

- Deverá ser um problema de saúde importante e preocupante, quer em termos de prevalência, quer pelos seus efeitos negativos na morbimortalidade e na qualidade de vida.

- A história natural do problema deve ser bem conhecida, saber-se que o precursor, precocemente identificado pelo teste de rastreio, conduz em continuidade à doença, causadora de morbimortalidade.

- A doença em questão deve ter uma fase de latência ou pré-sintomática, relativamente prolongada, antes dos sintomas e sinais se desenvolverem.

- O teste de rastreio a aplicar deve ser aceitável, designadamente em termos de validade (sensibilidade, especificidade, valor preditivo), morbilidade, riscos e custos.

- Para os casos de doença confirmada, deverá existir um tratamento aceitável em termos de efectividade, devendo a sua monitorização e acompanhamento estar devidamente assegurados.

- A doença detectada na fase pré-sintomática, tratada adequadamente, deve ter um resultado significativamente melhor, em termos de redução 


\section{DOSSIER}

da morbimortalidade e da melhoria da qualidade de vida, do que se for tratada só quando tiver expressão clínica.

Se olharmos para todas estas dimensões, podemos, com facilidade e à luz do que já foi referido no presente dossier, identificar que a prevenção selectiva ou indicada dos problemas ligados ao álcool através da detecção de casos contempla todos estes critérios, o que justifica uma atenção dirigida para esta matéria ao nível dos Cuidados de Saúde Primários.

\section{REFERÊNCIAS BIBLIOGRÁFICAS}

1. Büringher G, Künzel J. Evaluating preventive intervention in Europe. In: EMCDAEvaluating drug prevention in the Europen Union. Luxembourg: Office for Official Publications of the European Communities. European Monitoring Centre for Drug and Drug Addiction; 1998. p. 15-30.
2. UNODCCP: a participatory handbook for youth drug abuse prevention programes: a guide for development ADN improve. New York: United Nations Global Youth Network; 2002.

3. Institute of Medicine. Reducing risk for mental disorders:frontiers for preventive intervention research. Washington, DC: National Academy Press; 1994.

4. CSAP. Science-based substance abuse prevention: a guide. Rockville, MD: Center for Substance Abuse and Prevention; 2001.

5. Brown R. Factores de riesgo del abuso de substancias en los adolescentes.RET Revista de Toxicomanias 2002; 32: 20-5.

6. Wilson JM, Junger G. Principles and practice of screening for disease. Public Health Papers, 34. Geneve, World Health Organization, 1968. Cit. in: Morrell D. Epidemiology in general practice. Oxford: Oxford University Press; 1988. p. 37-9.

Endereço para correspondência Maria de Fátima Clemente Lima Rua Miguel Torga,

Edificio Miguel Torga, ${ }^{\circ} \mathrm{B}$

6290-366 Gouveia

E-mail: fclima@sapo.pt

\section{ABSTRACT}

Alcohol Related Problems are very important because they are the cause of many different physical, psychological and social conditions. Preventing the damage of alcohol related problems is a process involving many actors in society. To inform the population of those consequences are also primary health care professional's responsibility. In this text the authors classified prevention and consider its importance when concerning to alcohol related problems in primary health care; they justify also the reason of doing screening of these problems among the patients in PHC and how to promote an healthier life style among this population.

Key-words: Prevention; Alcohol Related Problems; Alcoholism; Screening; Case-finding. 